\title{
Effects of a comprehensive blood-sparing approach using body weight-adjusted miniaturized cardiopulmonary bypass circuits on transfusion requirements in pediatric cardiac surgery
}

\author{
Matthias Redlin, MD, ${ }^{\mathrm{a}}$ Helmut Habazettl, MD, PhD, ${ }^{\mathrm{a}, \mathrm{d}}$ Wolfgang Boettcher, ECCP, ${ }^{\mathrm{b}}$ \\ Marian Kukucka, MD, ${ }^{\mathrm{a}}$ Helge Schoenfeld, MD, ${ }^{\mathrm{c}}$ Roland Hetzer, MD, PhD, ${ }^{\mathrm{b}}$ and Michael Huebler, $\mathrm{MD}^{\mathrm{b}}$
}

\begin{abstract}
Objectives: Transfusion-free pediatric cardiac surgery remains a challenge, mainly owing to the mismatch between the cardiopulmonary bypass (CPB) priming volume and the infants' blood volume. Within a comprehensive blood-sparing approach, we developed body weight-adjusted miniaturized CPB circuits with priming volumes of 95, 110, and $200 \mathrm{~mL}$ for, respectively, infants weighing less than $3 \mathrm{~kg}, 3$ to $5 \mathrm{~kg}$ and $5 \mathrm{to} 16 \mathrm{~kg}$. We analyzed the effects of this approach on transfusion requirements and risk factors predisposing for blood transfusion.
\end{abstract}

\begin{abstract}
Methods: A total of 288 children with body weights between 1.7 and $15.9 \mathrm{~kg}$ were included and divided into 3 groups: No transfusion, postoperative transfusion only, and intraoperative and postoperative transfusion. Groups were compared by analysis of variance or analysis of variance on ranks. Risk factors predisposing for transfusion were identified by multivariate logistic regression.

Results: Of the infants, $24.7 \%$ required no transfusion, $23.6 \%$ received postoperative transfusion only and $51.7 \%$ received intraoperative and postoperative transfusion. Groups differed by age, body weight, and size and by duration of surgery, $\mathrm{CPB}$, and aortic crossclamp $(P<.00001)$. Body weight $(P<.00001)$, CPB duration $(P<.00001)$, and persisting cyanosis $(P=.03)$ were predictors of intraoperative and postoperative transfusion, whereas body weight $(P=.00095)$, reoperations $(P=.0051)$, and cyanotic heart defects $(P=.035)$ were associated with postoperative transfusion only.

Conclusions: Our blood-sparing approach allows for transfusion-free surgery in a substantial number of infants. The strongest predictors of transfusion requirement, body weight and complexity of surgery as reflected by CPB duration, are not amenable to further improvements. Better preservation of the coagulatory system might allow for reduction of postoperative transfusion requirements. (J Thorac Cardiovasc Surg 2012;144:493-9)
\end{abstract}

In the past decades pediatric cardiac surgery underwent numerous improvements in surgical techniques, cardiopulmonary bypass (CPB) equipment, and postoperative intensive care. Yet, transfusion of homologous blood products is still required in most cases mostly because of the mismatch between the priming volumes of the CPB circuits and the patients' blood volumes. In the general population, transfusion, albeit necessary for maintenance of adequate oxygen transport, may increase the risks for postoperative complications such as transfusion-transmitted infection ${ }^{1,2}$ or postoperative mortality. ${ }^{3,4}$ Previous studies confirmed adverse effects of blood transfusion on short-term outcome

\footnotetext{
From the Departments of Anesthesiology and Cardiothoracic and Vascular Surgery, ${ }^{\mathrm{b}}$ German Heart Institute, Berlin; the Institute of Transfusion Medicine ${ }^{\mathrm{c}}$ and the Department of Physiology, ${ }^{\mathrm{d}}$ Charité, University Medicine Berlin, Berlin, Germany. Disclosures: Authors have nothing to disclose with regard to commercial support. M.R. and H.H. contributed equally to the study.

Received for publication Sept 30, 2011; revisions received Dec 7, 2011; accepted for publication Jan 4, 2012; available ahead of print Feb 1, 2012.

Address for reprints: Helmut Habazettl, MD, PhD, Institute of Physiology, Thielallee

71, 14195 Berlin, Germany (E-mail: helmut.habazettl@ charite.de). $0022-5223 / \$ 36.00$

Copyright (c) 2012 by The American Association for Thoracic Surgery doi:10.1016/j.jtcvs.2012.01.008
}

in pediatric cardiac surgery by demonstrating a link between the amount of transfused blood with the length of hospital stay ${ }^{5}$ or the duration of assisted ventilation. ${ }^{6,7}$ To minimize the requirement for transfusion of homologous blood products, we developed a comprehensive bloodsparing approach that includes the following: (1) avoiding all unnecessary blood sampling; (2) meticulous surgical technique aimed at minimizing blood loss; (3) cell salvage technique and retransfusion of autologous red blood cells; (4) a defined transfusion trigger of hemoglobin concentration less than $7 \mathrm{~g} / \mathrm{dL}$ during CPB while monitoring cerebral oxygenation by near-infrared spectroscopy to detect and avoid cerebral hypoxia ${ }^{8}$; and, most important, (5) minimizing the priming volume of the CPB circuit while maintaining all necessary safety features. ${ }^{9}$ Here we report the impact of this approach on the requirements for transfusion of homologous blood products in 288 pediatric patients with body weights of less than $16 \mathrm{~kg}$ treated with this approach at our institution between May 2007 and September 2010. In addition, the factors that predict blood transfusion when using our blood-sparing approach are retrospectively analyzed. 


\section{Abbreviations and Acronyms \\ $\mathrm{CI}=$ confidence interval \\ $\mathrm{CPB}=$ cardiopulmonary bypass \\ DHCA $=$ deep hypothermic circulatory arrest \\ RACHS $=$ Risk Adjustment in Congenital Heart Surgery}

\section{METHODS \\ Patients}

Between May 2007 and September 2010, 1120 infants with body weights of less than $16 \mathrm{~kg}$ were operated on at our institution for various indications, 822 with the use of CPB. Of these 1120 infants, 288 were treated by our team of 1 cardiac surgeon, 1 anesthetist, and 1 of 2 perfusionists dedicated to the blood-sparing approach. Primary diagnoses are listed in Table 1; however, the majority of patients had combined cardiac defects. Age ranged from 3 days to 4.8 years, median 161 days (Table 2), and body weight from 1.7 to $15.9 \mathrm{~kg}$, median $5.8 \mathrm{~kg}$. Fifty-two (18\%) procedures were reoperations, $156(54 \%)$ infants had cyanotic heart defects, and 25 $(9 \%)$ infants remained cyanotic after surgery. The retrospective data analysis was approved by the institutional review board.

\section{CPB and Surgery}

Two different body weight-adapted CPB circuits were redesigned to minimize as much as possible the priming volumes. The CPB circuit used for infants with body weights of less than $5 \mathrm{~kg}$ has recently been described. ${ }^{9,10}$

A Stöckert S5 mast mounted console (Stöckert Instrumente $\mathrm{GmbH}, \mathrm{Mu}-$ nich, Germany) was modified by shortening as much as possible all tubing connections. All tubings were 3/16 inch internal diameter (ID) except the arterial pump boot (1/4 inch) and suction lines (1/8 inch). Low prime oxygenator (KIDS D100; Sorin, Mirandola, Italy) and arterial line filter (D130, Sorin) were used. Vacuum assist was used to increase venous return. This modified system has a total priming volume of $110 \mathrm{~mL}$, which was further reduced to $95 \mathrm{ml}$ for neonates $<3 \mathrm{~kg}$ body weight by using 3/16 inch ID tubing for the arterial pump boot.

Because of the flow limitation of this system, the CPB circuit was modified for infants with body weights between 5 and $16 \mathrm{~kg}$ by replacing the oxygenator (Capiox Baby RX05; Terumo Cardiovascular Systems, Ann Arbor, Mich) and the arterial line filter (D736; Sorin, Mirandola, Italy), resulting in a priming volume of $200 \mathrm{~mL} .^{11}$

Asanguineous priming of the CPB was used when the estimated hemoglobin concentration remained above $7 \mathrm{~g} / \mathrm{dL}$. Hemoglobin concentrations were assessed immediately after mixing of the priming volume with the patients' blood, and packed red blood cells were added when the transfusion trigger of a hemoglobin level less than $7 \mathrm{~g} / \mathrm{dL}$ was reached. Tranexamic acid in a dose of $10 \mathrm{mg} \cdot \mathrm{kg}^{-1} \cdot \mathrm{h}^{-1}$ was added for antifibrinolysis. Moderate hypothermia to various degrees was induced according to the expected duration of $\mathrm{CPB}$. Deep hypothermia to $14^{\circ} \mathrm{C}$ to $17^{\circ} \mathrm{C}$ was induced for deep hypothermic circulatory arrest (DHCA; $\mathrm{n}=31$ ). Postoperative transfusion of homologous blood products was performed on the decision of the attending physicians. Decreased hemoglobin concentration owing to blood loss and hemodynamic instability were the major indications for transfusion.

\section{Monitoring}

Heart rate, arterial and central venous pressure, pulse-oximetric oxygen saturation, and temperatures were continuously recorded. Arterial blood gases and lactate concentrations were analyzed (Rapidlab 865; Siemens Healthcare Diagnostics, Inc, Deerfield, Ill) before surgery, after the onset

TABLE 1. Primary diagnoses

\begin{tabular}{lr}
\hline \multicolumn{1}{c}{ Primary diagnosis } & No. \\
\hline Atrial septal defect & 21 \\
Ventricular septal defect & 48 \\
Atrioventricular septal defect & 42 \\
Sinus venosus defect & 7 \\
Transposition of the great arteries & 39 \\
Hypoplastic left heart syndrome & 13 \\
Tetralogy of Fallot & 23 \\
Double-outlet right ventricle & 6 \\
Persistent Truncus arteriosus & 4 \\
Pulmonary atresia & 12 \\
Tricuspid atresia & 4 \\
Total anomalous pulmonary venous connection & 4 \\
Aortic stenosis (4 supravalvular) & 11 \\
Hypoplastic aortic arch & 7 \\
Others & 47 \\
\hline
\end{tabular}

Only primary diagnoses are listed. Most infants presented with combined congenital heart defects.

of $\mathrm{CPB}$, at variable intervals during $\mathrm{CPB}$, briefly before termination of $\mathrm{CPB}$, and during chest closure (after $\mathrm{CPB}$ ). Central venous blood gases were analyzed before $\mathrm{CPB}$ and after surgery.

\section{Statistics}

Patient characteristics and outcome data were compared between groups by analysis of variance on ranks. Incidence data were analyzed by the $\chi^{2}$ test. Time course of hemoglobin concentrations among groups was analyzed by 2 -way repeated measures analysis of variance. Predictors of transfusion were determined by univariate logistic regression. All parameters with $P<.1$ in univariate analyses were included in a multivariate logistic regression model. Because of substantial collinearity among age, size, and body weight as well as among duration of surgery, CPB, and aortic crossclamp, only the parameters that best predicted transfusion in univariate analyses (ie, body weight and duration of $\mathrm{CPB}$ ) were included in the multivariate analyses.

\section{RESULTS}

In $139(48.3 \%)$ patients surgery could be completed without blood transfusion, but 68 of these received transfusion of homologous blood products during the postoperative period. Accordingly, patients were assigned to 3 different groups: no transfusion $(\mathrm{n}=71 ; 24.7 \%)$, postoperative transfusion only $(\mathrm{n}=68 ; 23.6 \%)$, and intraoperative and postoperative transfusion $(\mathrm{n}=149 ; 51.7 \%)$. Distribution of body weight among these groups is given in Figure 1. Patient data according to these groups are listed in Table 2. Infants who required blood transfusions were significantly younger, smaller, and lighter than those who did not and, also, those who received intraoperative and postoperative transfusion were smaller and lighter than those who received postoperative transfusion only. Similarly, complexity of surgery, reflected as durations of surgery, CPB, and aortic crossclamp, was greatest in the infants requiring intraoperative and postoperative transfusions, followed by those requiring postoperative transfusions only. The rates of reoperations were similar among groups, but DHCA 
TABLE 2. Patient and procedural data

\begin{tabular}{|c|c|c|c|c|}
\hline & No transfusion & Postop transfusion only & Intraop and postop transfusions & $P$ value \\
\hline $\mathrm{N}(\%)$ & $71(24.7)$ & $68(23.6)$ & $149(51.7)$ & \\
\hline Age (d) & $600(234 ; 946)$ & $151(95 ; 334)^{*}$ & $114(42 ; 200)^{*}$ & $<.00001$ \\
\hline Body weight $(\mathrm{kg})$ & $9.7(6.7 ; 12.6)$ & $6.0(4.2 ; 8.7)^{*}$ & $4.9(3.6 ; 6.5)^{*}, \dagger$ & $<.00001$ \\
\hline Size $(\mathrm{cm})$ & $81(68 ; 93)$ & $64(55 ; 75)^{*}$ & $58(53 ; 66)^{*}, \dagger$ & $<.00001$ \\
\hline Duration of operation (min) & $118(96 ; 147)$ & $149(113 ; 197)^{*}$ & $189(149 ; 253)^{*}, \dagger$ & $<.00001$ \\
\hline $\mathrm{CPB}$ duration (min) & $57(38 ; 82)$ & $78(54 ; 113)^{*}$ & $115(82 ; 162)^{*}, \dagger$ & $<.00001$ \\
\hline Crossclamp time (min) & $34(21 ; 52)$ & $53(28 ; 77)^{*}$ & $59(38 ; 87)^{*}$ & $<.00001$ \\
\hline Reop, N (\%) & $9(12.7)$ & $16(23.5)$ & $27(18.1)$ & .251 \\
\hline DHCA, N (\%) & $1(1.4)$ & $2(2.9)$ & $28(18.8)^{*}, \dagger$ & .00003 \\
\hline Preop cyanosis, $N(\%)$ & $17(23.9)$ & $41(60.3)^{*}$ & $98(65.8)^{*}$ & $<.00001$ \\
\hline Persistent cyanosis, N (\%) & $3(4.2)$ & $4(5.9)$ & $18(12.1)$ & .10 \\
\hline PRBC, $N(\%)$ & & $66(97)$ & $149(100)$ & n.d. \\
\hline Volume $(\mathrm{mL} / \mathrm{kg})$ & & $23(19 ; 30)$ & $38(26 ; 67)$ & $<.00001$ \\
\hline FFP, N $(\%)$ & & $25(37)$ & $137(92)$ & $<.00001$ \\
\hline $\mathrm{TC}, \mathrm{N}(\%)$ & & $2(3)$ & $48(32)$ & $<.00001$ \\
\hline
\end{tabular}

Continuous data are represented as median and (25;75) percentiles, rates as absolute numbers $\mathrm{N}$ and $(\%)$. Groups were compared by analysis of variance on ranks and $\chi^{2}$ test as appropriate. $C P B$, Cardiopulmonary bypass; $D H C A$, deep hypothermic circulatory arrest; $P R B C$, packed red blood cells; $F F P$, fresh frozen plasma; $T C$, thrombocyte concentrates; n.d., not determined. $* P<.05$ versus no transfusion. $\dagger P<.05$ versus postoperative transfusion only.

was more frequently used in infants who required intraoperative and postoperative transfusions. In both groups with transfusion, cyanotic heart defects were more frequent, and there was a trend for more frequent persisting cyanosis in the group with intraoperative and postoperative transfusion. Total transfused volume of packed red blood cells and the number of infants who additionally received fresh frozen plasma or thrombocyte concentrates were significantly lower in the group with postoperative transfusion only versus intraoperative and postoperative transfusion.

The time course of hemoglobin concentrations during surgery is shown in Figure 2. Hemoglobin concentration was similar among groups before surgery and decreased markedly in all groups during CPB. Toward the end of surgery, hemoglobin concentration slightly increased from its nadir during CPB in the groups without intraoperative transfusion, but it did not reach the preoperative values. In contrast, in the transfused group, hemoglobin concentration started to increase already toward the end of CPB and was not different from the preoperative value at the end of surgery.

To assess the parameters that might determine the need for either intraoperative and postoperative transfusion or postoperative transfusion only, we applied univariate logistic regression (Table 3). Age, body weight, and size were negatively correlated with transfusion. Namely, each additional kilogram of body weight was associated with an odds ratio (confidence interval $[\mathrm{CI}] ; P$ value) of $0.77(\mathrm{CI}$, $0.71-0.84 ; P<.00001)$ for intraoperative and postoperative transfusion and 0.81 (CI, 0.73-0.89; $P=.00004)$ for postoperative transfusion only. Preoperative hemoglobin concentration was not associated with transfusion nor did postoperative hemoglobin concentration affect the need for postoperative transfusion. Reoperations tended to increase the risk for postoperative transfusion only $(P=.10)$. The complexity of surgery, assessed by duration of surgery, CPB, and aortic crossclamp, strongly determined the need for transfusion. Namely, each additional minute of CBP was associated with an odds ratio of 1.02 (CI, 1.01-1.03; $P<.00001)$ for intraoperative and postoperative transfusion and $1.02(\mathrm{CI}, 1.01-1.03 ; P=.00038)$ for postoperative transfusion only. DHCA markedly increased the need for intraoperative and postoperative transfusion (odds ratio, 10.49; CI, 3.11-35.38; $P=.00015$ ) but not postoperative transfusion only $(P=.54)$. Infants with cyanotic heart defects had a higher need for intraoperative and postoperative transfusion (odds ratio, 2.68; CI, 1.66-4.33; $P=.00005$ ) and postoperative transfusion only (odds ratio, 4.82; CI, 2.32-10.01; $P=.00002$ ). Palliative surgery with persisting cyanosis was associated with a higher need for intraoperative and postoperative transfusion(odds ratio, 3.65; CI,1.32-10.08; $P=.012$ ) but not for postoperative transfusion only requirement $(P=.66)$.

To assess which parameters independently predicted the need for blood transfusion, we used multivariate logistic regression (Table 3, lower part). All parameters with $P=.10$ or smaller in one of the univariate analyses were included in the multivariate model, except for age and size because of colinearity with body weight, and duration of surgery and aortic crossclamp because of colinearity with CPB duration. Independent predictors of the need for intraoperative and postoperative transfusion were body weight, CPB duration, and palliative surgery with persisting cyanosis, but not DHCA or cyanotic heart defects. Predictors for postoperative transfusion only were body weight, reoperations, and cyanotic heart defects. Complexity of surgery as reflected by $\mathrm{CPB}$ duration showed a strong trend to also increase the need for postoperative transfusion only $(P=.072)$. 


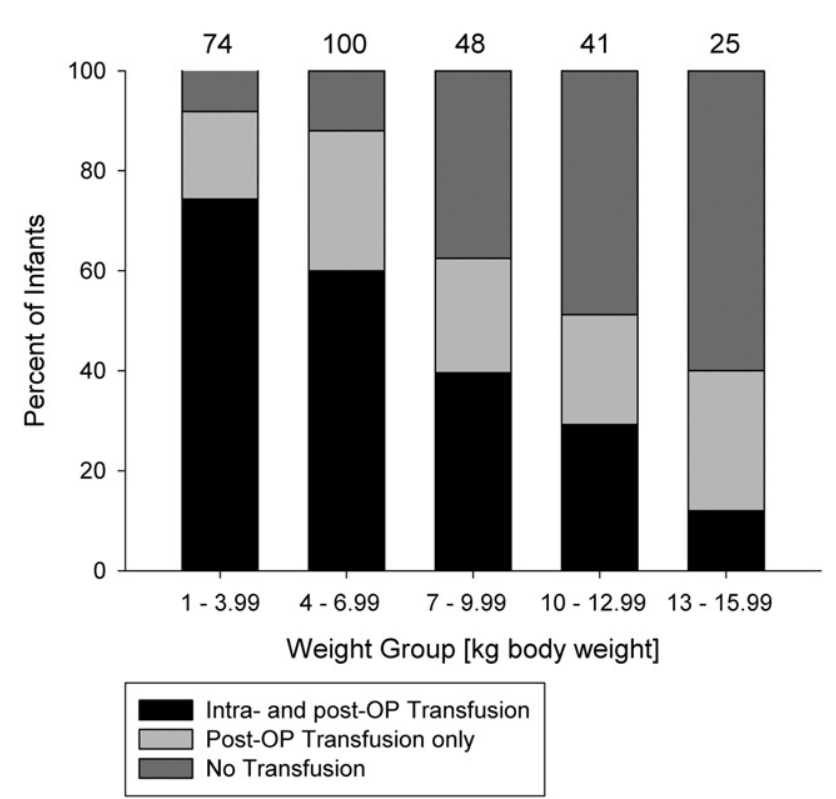

FIGURE 1. Distribution of infants among the groups with no transfusion, postoperative transfusion only, and intraoperative and postoperative transfusion is analyzed according to body weight. While $26 \%$ of neonates in the lowest weight group were operated on without blood transfusion, only $8 \%$ remained without any transfusion also in the postoperative period. This rate increased continuously with body weight to $60 \%$ among infants with body weights between 13 and $16 \mathrm{~kg}$. Conversely, the rate of intraoperative and postoperative transfusion decreased with body weight, from $74 \%$ to $12 \%$.

\section{DISCUSSION}

Implementation of body weight-adjusted miniaturized CPB circuits for pediatric cardiac surgery combined with a comprehensive strategy to avoid unnecessary hemodilution allowed for completion of surgery without transfusion of homologous blood products in $48.3 \%$ of infants. Including the postoperative period, $24.7 \%$ of the infants could be treated without any transfusion. In multivariate logistic regression analyses, low body weight, complexity of surgery as reflected by duration of $\mathrm{CPB}$, and persisting cyanosis after palliative surgery were independent predictors for intraoperative and postoperative transfusion. Postoperative transfusion only was independently associated with low body weight, reoperations, and cyanotic heart defects.

Minimizing hemodilution in pediatric cardiac surgery may have several potential benefits. Oxygen transport capacity is maintained and the coagulatory system is better preserved, which may reduce postoperative bleeding. Most important, it may help to avoid intraoperative or postoperative transfusion of homologous blood products. Transfusion is generally associated with a number of risks including transmission of infectious agents, ${ }^{12}$ inflammatory responses, ${ }^{13,14}$ or transfusion-related acute lung injury. ${ }^{15,16}$ In the setting of pediatric cardiac surgery, transfusion has recently been associated with adverse short-term outcome

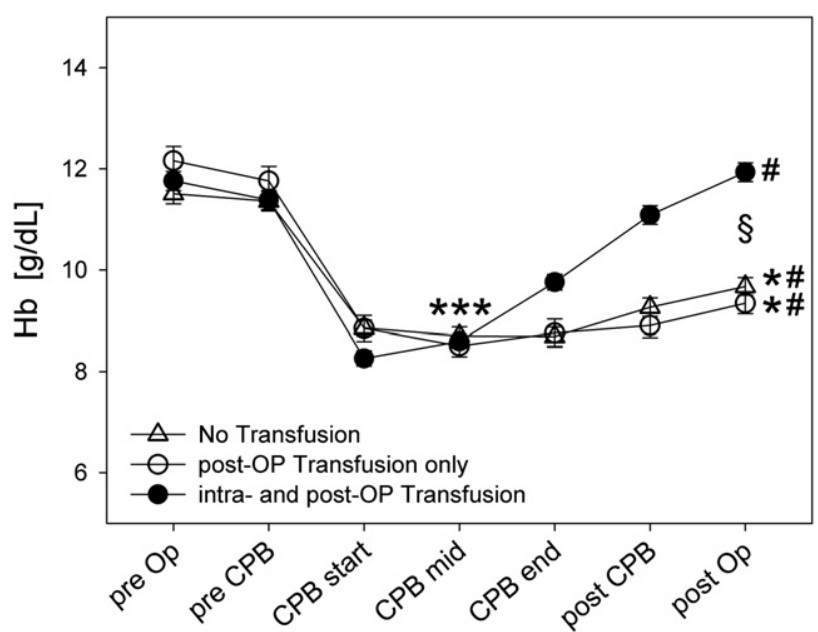

FIGURE 2. The course of hemoglobin concentrations during surgery is given for the 3 groups. Data are means \pm standard error of the mean. Only time points of major interest, that is, preoperative, CPB mid, and postoperative, were included in the 2-way repeated measures analysis of variance. $* P<.00001$ versus preoperative; $* * *$ all 3 groups $P<.00001$ versus pre-OP; $\# P<.01$ versus CPB mid; $\S P<.00001$ intraoperative and postoperative transfusion versus postoperative transfusion only and no transfusion. $H b$, Hemoglobin concentration; $C P B$, cardiopulmonary bypass.

such as increased rate of infection, ${ }^{17}$ length of mechanical ventilation, ${ }^{6,7}$ and length of hospital stay. ${ }^{5}$

Accordingly, several successful attempts to avoid transfusion in pediatric cardiac surgery by using miniaturized $\mathrm{CPB}$ circuits and stringent transfusion triggers have been reported. ${ }^{18-21}$ The major differences in the present approach are that the priming volumes of the CBP circuits used are considerably smaller and, in addition to intraoperative transfusion, incidence of postoperative transfusion was analyzed as well. Also, in some of the previous reports only infants with low-complexity surgery such as closure of ventricular septal defect were included, ${ }^{19}$ and important safety features such as arterial line filter were eliminated. ${ }^{19}$ In some studies transfusion-trigger hematocrit was rather low at $15 \%,{ }^{18,19}$ although the hemoglobin concentration of $7 \mathrm{~g} / \mathrm{dL}$ triggering transfusion in the present study would correspond to a hematocrit value of $21 \%$. The single study that is best comparable with the present report by the mixed patient population and a transfusion trigger of hematocrit value less than $20 \%$ is by Kotani and associates. ${ }^{20}$ They used $\mathrm{CPB}$ circuits with priming volumes of 300 and $500 \mathrm{~mL}$ and completed surgery without transfusion in $49.3 \%$ of the infants, which is about the same as the $48.3 \%$ in the present study. Thus it would seem that the further reduction of priming volumes had little effect on transfusion requirements. However, the median age and body weight in that study were 23.5 months (range, 2-124 months) and $10.4 \mathrm{~kg}$ (range, $5.0-19.9 \mathrm{~kg}$ ) compared with 5.4 months (range, 0-58 months) and $5.8 \mathrm{~kg}$ (range, $1.7-15.9 \mathrm{~kg}$ ), respectively, in the present study. Considering the strong 
TABLE 3. Risk factors for transfusion results of logistic regression analyses to determine the risk factors predisposing for intraoperative and postoperative transfusion and postoperative transfusion only

\begin{tabular}{|c|c|c|c|c|}
\hline & \multicolumn{2}{|c|}{ Intraop and postop transfusion } & \multicolumn{2}{|c|}{ Postop transfusion only } \\
\hline & Odds ratio; CI & $P$ value & Odds ratio; CI & $P$ value \\
\hline \multicolumn{5}{|l|}{ Univariate logistic regression } \\
\hline Age (y) & $0.43 ; 0.32-0.57$ & $<.00001$ & $0.59 ; 0.44-0.79$ & .00036 \\
\hline BW (kg) & $0.77 ; 0.71-0.84$ & $<.00001$ & $0.81 ; 0.73-0.89$ & .00004 \\
\hline Size $(\mathrm{cm})$ & $0.94 ; 0.92-0.96$ & $<.00001$ & $0.95 ; 0.93-0.97$ & .00002 \\
\hline Reop & $1.01 ; 0.55-1.84$ & .98 & $2.12 ; 0.87-5.19$ & .10 \\
\hline Preop hemoglobin (g/dL) & $0.99 ; 0.89-1.10$ & .81 & $1.18 ; 0.99-1.40$ & .065 \\
\hline Postop hemoglobin (g/dL) & n.d. & n.d. & $0.87 ; 0.69-1.09$ & .22 \\
\hline Op duration (min) & $1.02 ; 1.01-1.02$ & $<.00001$ & $1.02 ; 1.01-1.03$ & .00015 \\
\hline CPB duration (min) & $1.02 ; 1.01-1.03$ & $<.00001$ & $1.02 ; 1.01-1.03$ & .00038 \\
\hline Crosslamp time (min) & $1.01 ; 1.01-1.02$ & .00005 & $1.02 ; 1.00-1.03$ & .0052 \\
\hline DHCA & $10.49 ; 3.11-35.38$ & .00015 & $2.12 ; 0.18-23.95$ & .54 \\
\hline Preop cyanosis & $2.68 ; 1.66-4.33$ & .00005 & $4.82 ; 2.32-10.01$ & .00002 \\
\hline Persist. cyanosis & $3.65 ; 1.32-10.08$ & .012 & $1.42 ; 0.31-6.58$ & .66 \\
\hline \multicolumn{5}{|l|}{ Multivariate logistic regression } \\
\hline BW (kg) & $0.80 ; 0.73-0.88$ & $<.00001$ & $0.80 ; 0.70-0.91$ & .00095 \\
\hline CPB duration (min) & $1.02 ; 1.01-1.02$ & $<.00001$ & $1.01 ; 1.00-1.02$ & .072 \\
\hline Reop & n.d. & n.d. & $6.01 ; 1.71-21.05$ & .0051 \\
\hline Preop hemoglobin (g/dL) & n.d. & n.d. & $0.82 ; 0.62-1.07$ & .14 \\
\hline DHCA & $1.91 ; 0.50-7.31$ & .34 & $1.17 ; 0.08-17.67$ & .91 \\
\hline Preop cyanosis & $1.07 ; 0.56-2.03$ & .84 & $3.46 ; 1.09-10.98$ & .035 \\
\hline Persist. cyanosis & $3.44 ; 1.12-10.59$ & .03 & n.d. & n.d. \\
\hline
\end{tabular}

Only parameters with $P<.1$ in the univariate analyses were included in the multivariate logistic regression models. $P$ values $<.05$ in multivariate analyses are given in boldface type. $C I$, Confidence interval; $B W$, body weight; $C P B$, cardiopulmonary bypass; $D H C A$, deep hypothermic circulatory arrest; $n$.d., not determined.

association of age and body weight with transfusion requirements reported in previous studies ${ }^{17,20}$ and the present study, we may conclude that the smaller CPB circuits used in the present study allowed for a similar rate of transfusion-free surgery in a much younger and smaller patient population than in that previous report. This conclusion is supported by comparison of intraoperative transfusion rates by body weight-based analysis. Whereas the smallest child in the study by Kotani and associates ${ }^{20}$ had a body weight of 5 $\mathrm{kg}$, our population included 137 infants with body weights of 1.7 to $5 \mathrm{~kg}$ and $30 \%$ of these concluded cardiac surgery without transfusion. In the weight group of 6 to $10 \mathrm{~kg}$, transfusion-free surgery was achieved in $57 \%$ of 95 infants compared with $29 \%$ of 279 infants in the report by Kotani and associates, ${ }^{20}$ whereas the transfusion-free rate in the group with 11 to $15 \mathrm{~kg}$ was $79 \%$ of 56 infants in our study compared with $67 \%$ of 184 patients in the previous study.

Miyaji and colleagues ${ }^{21}$ used a CPB circuit with a priming volume of $140 \mathrm{~mL}$ for infants with $4-$ to $7-\mathrm{kg}$ body weight and achieved transfusion-free surgery in an impressive $64 \%$ of 70 patients with mixed diagnoses. The main transfusion trigger was a hematocrit value of less than $20 \%$, which is similar to our study. The major differences that might contribute to the greater rate of transfusion-free surgery despite the larger priming volume are the number of infants with body weight of less than $4 \mathrm{~kg}$ in our patient population (74/288) and the larger rate of less complex surgical procedures (35/70 patients received only ventricular or atrial septal defect closure) in that previous study.

The second focus of this study was to determine the risk factors for intraoperative and postoperative transfusion to identify additional interventions that might help to reduce the rate of blood transfusions. Previously, Szekely and coworkers ${ }^{17}$ performed multivariate linear regression analyses to determine the predictors of the volume of transfused homologous blood products (until 24 hours after surgery) in a mixed population of infants who were operated on with conventional CPB circuits (priming volume not given). In accordance with our results, they identified body weight and crossclamp time as strong predictors of transfused volume. Similar to the present study, Kotani, ${ }^{20}$ Miyaji, ${ }^{21}$ and their associates used multivariate logistic regression analysis to determine the risk factors for intraoperative transfusion and also identified body weight and CPB time as strong independent predictors. Preoperative hematocrit value was associated with the need for transfusion in only 1 of these studies. ${ }^{20}$ This was not confirmed in the present study, in which preoperative hemoglobin concentration was not different among groups (Figure 2) and did not affect the rate of transfusion. This is in contrast to a recent study on neonates undergoing the arterial switch operation for transposition of the great arteries, in which hemoglobin concentration was significantly lower in infants requiring intraoperative transfusion. ${ }^{9} \mathrm{We}$, therefore, analyzed the 
subgroup with cyanotic heart defects in more detail. Hemoglobin concentration in cyanotic infants was significantly higher than in the noncyanotic group $(12.7 \pm 2.2$ vs 10.7 $\pm 1.5 ; P<.00001$ rank sum test). Within the noncyanotic group, preoperative hemoglobin concentration was similar in infants receiving no transfusion $(10.8 \pm 0.8)$, postoperative transfusion only (10.5 \pm 1.3$)$, or intraoperative and postoperative transfusion $(10.7 \pm 2.1)$. In contrast, in the cyanotic group, preoperative hemoglobin concentration was significantly higher in the group with no transfusion $(13.7 \pm 1.9)$ than in the group with intraoperative and postoperative transfusion $(12.3 \pm 2.2)$, whereas the value for infants with postoperative transfusion only was in between (13.2 $\pm 2.2 ; P=.005$, analysis of variance on ranks). Accordingly, univariate logistic regression within the subgroup of cyanotic infants indicates significant influence of preoperative hemoglobin concentration on the need for intraoperative and postoperative transfusion (odds ratio 0.81; CI, $0.70-0.95 ; P=.0076)$ but not for postoperative transfusion only $(P=.42)$. Because they constitute the major difference between this and previous studies, it seems that the very low priming volume CPB circuits used in the present study lessen the influence of preoperative hemoglobin concentration on intraoperative transfusion requirements. However, further studies would be needed to confirm this speculation. The only additional independent predictor of intraoperative and postoperative transfusion was palliative surgery with persisting cyanosis present in 25 infants, which is not surprising, because a higher target hemoglobin concentration on weaning from CPB is necessary in these patients to maintain sufficient oxygen delivery despite reduced oxygen saturation. Accordingly, $72 \%$ of these infants received intraoperative and postoperative transfusion, $16 \%$ postoperative transfusion only, and only $12 \%$ remained without any transfusion. These infants may also contribute to the increase in hemoglobin concentration toward the end of $\mathrm{CPB}$ and the end of surgery (Figure 2).

For the analysis of risk factors for postoperative transfusion only in the subgroup of infants who completed surgery without transfusion, we are not aware of any previous studies addressing this question. Low body weight also increased the risk of transfusion, whereas CPB time, which we consider to reflect the complexity of surgery, did not. That would indicate that the complexity of surgery has a stronger influence on intraoperative than on postoperative transfusion requirements. Reoperations were identified as a strong independent predictor of postoperative transfusion only with an odds ratio of 6.01 (CI, 1.71-21.05). Although postoperative blood loss was not monitored in this study, we should ascribe this observation to the greater risk of bleeding in these patients. Why preoperative cyanosis, which is corrected during surgery, should increase the transfusion requirements during the postoperative period remains unclear.

\section{Limitations}

The general limitations of retrospective analyses have recently been summarized ${ }^{22}$ and include the "inability to (1) harvest data on all important covariates (variables or risk factors), (2) control covariates, and (3) standardize indications for the primary intervention" and apply to the present study as well. A large prospective study with a wellstandardized clinical approach, standardized transfusion triggers, and careful selection of potential risk factors determining the rate of transfusion would be necessary to avoid this problem. Another limitation may be the selection of CPB time to reflect the complexity of cardiac surgery. Previous studies determined the Risk Adjustment in Congenital Heart Surgery (RACHS) category for this purpose. ${ }^{17,20,21}$ However, in contrast to CPB time, in all these studies RACHS category was associated with transfusion only in the univariate, but not in the multivariate, analyses and we conclude that CPB time may better represent the impact of the surgical complexity on transfusion requirements than the RACHS category. Although the risks of transfusion of blood products are widely known, clinical outcome was not assessed in this study, which focused on the ability to avoid blood transfusion by using a very low priming volume $\mathrm{CPB}$ circuit and on the risk factors for intraoperative and postoperative transfusion with this approach. Finally, there are no unanimous data on the safe hematocrit or hemoglobin level in neonates or infants during CPB. ${ }^{9}$ Lower psychomotor development has been associated with a hematocrit level during CPB of less than $22 \%{ }^{23-25}$ or less than $23.5 \%{ }^{26}$ On the other hand, a hematocrit level of $20 \%$ as a transfusion trigger did not seem to negatively affect psychomotor development in another, albeit retrospective, study. ${ }^{21}$ In a large prospective study in critically ill infants, a transfusion trigger of $7.0 \mathrm{~g} / \mathrm{dL}$ hemoglobin concentration was not inferior to a trigger of 9.5 $\mathrm{g} / \mathrm{dL}$ concerning clinical outcome. ${ }^{27}$ In a subgroup analysis, similar results were obtained for infants who had undergone cardiac surgery. ${ }^{28}$ Although psychomotor development was not included in the outcome parameters and the situation of infants on intensive care units is not directly comparable with the situation of $\mathrm{CPB}$, one might speculate that during the latter condition infants are at less risk of hypoxia because oxygen delivery is well monitored and controlled via the CPB flow rate. While the hematocrit transfusion trigger of $21 \%$ in our protocol is in between these values, one must also appreciate that cerebral balance of oxygen delivery to demand depends not only on hematocrit but also on CPB flow rate and temperature, which also differ among these studies.

\section{CONCLUSIONS}

In conclusion, we demonstrated that use of body weightadjusted low-volume $\mathrm{CPB}$ circuits with a minimal priming 
volume of down to $95 \mathrm{~mL}$ allows for completion of cardiac surgery without transfusion in nearly $50 \%$ of infants in a mixed patient population with body weights between 1.7 and $16 \mathrm{~kg}$ and variable surgical complexity. Nearly $25 \%$ of these infants remained without transfusion during the whole postoperative period. The concerted effort of surgeon, anesthetist, and perfusionist to avoid transfusion was pivotal to achieve these results, in addition to the lowvolume CPB circuits. Body weight, CPB time, and palliative surgery with persisting cyanosis were independent predictors of intraoperative transfusion. In the subgroup of infants without intraoperative transfusion, body weight, reoperation, and cyanotic heart defects determined the need for postoperative transfusion. None of these risk factors seems easily amenable to interventions with the goal of further reducing transfusion rates. Thus transfusion-free pediatric cardiac surgery remains a challenge, especially in low-weight infants. Better preservation of the coagulatory system by improved biocompability of the CPB circuits might reduce postoperative bleeding and transfusion requirements during this period. Further research should address the safety of such approaches using very low priming volume $\mathrm{CPB}$ circuits and assess the safe hematocrit concentration during different $\mathrm{CPB}$ flow and temperature conditions.

We acknowledge the meticulous work of Argid and Raimund Rutenberg to compile the comprehensive data set for this study.

\section{References}

1. Dodd RY. The risk of transfusion-transmitted infection. N Engl J Med. 1992;327: 419-21.

2. Kuehnert MJ, Roth VR, Haley NR, Gregory KR, Elder KV, Schreiber GB, et al. Transfusion-transmitted bacterial infection in the United States, 1998 through 2000. Transfusion. 2001;41:1493-9.

3. Michalopoulos A, Tzelepis G, Dafni U, Geroulanos S. Determinants of hospital mortality after coronary artery bypass grafting. Chest. 1999;115:1598-603.

4. Engoren MC, Habib RH, Zacharias A, Schwann TA, Riordan CJ, Durham SJ. Effect of blood transfusion on long-term survival after cardiac operation. Ann Thorac Surg. 2002;74:1180-6.

5. Salvin JW, Scheurer MA, Laussen PC, Wypij D, Polito A, Bacha EA, et al. Blood transfusion after pediatric cardiac surgery is associated with prolonged hospital stay. Ann Thorac Surg. 2011;91:204-10.

6. Szekely A, Sapi E, Kiraly L, Szatmari A, Dinya E. Intraoperative and postoperative risk factors for prolonged mechanical ventilation after pediatric cardiac surgery. Paediatr Anaesth. 2006;16:1166-75

7. Kipps AK, Wypij D, Thiagarajan RR, Bacha EA, Newburger JW. Blood transfusion is associated with prolonged duration of mechanical ventilation in infants undergoing reparative cardiac surgery. Pediatr Crit Care Med. 2011;12:52-6.

8. Redlin M, Koster A, Huebler M, Boettcher W, Nagdyman N, Hetzer R, et al. Regional differences in tissue oxygenation during cardiopulmonary bypass for correction of congenital heart disease in neonates and small infants: relevance of near-infrared spectroscopy. J Thorac Cardiovasc Surg. 2008;136:962-7.
9. Redlin M, Huebler M, Boettcher W, Kukucka M, Schoenfeld H, Hetzer R, et al. Minimizing intraoperative hemodilution by use of a very low priming volume cardiopulmonary bypass in neonates with transposition of the great arteries. J Thorac Cardiovasc Surg. 2011;142:875-81.

10. Huebler M, Habazettl H, Boettcher W, Kuppe H, Hetzer R, Redlin M. Transfusion-free complex cardiac surgery with use of deep hypothermic circulatory arrest in a preterm 2.96-kg Jehova's Witness neonate. Tex Heart Inst J. 2011;38:562-4.

11. Huebler M, Boettcher W, Koster A, Stiller B, Kuppe H, Hetzer R. Transfusionfree cardiac reoperation in an 11-kg Jehovah's Witness child by use of a minimized cardiopulmonary bypass circuit. Tex Heart Inst J. 2007;34:108-11.

12. Chiavetta JA, Escobar M, Newman A, He Y, Driezen P, Deeks S, et al. Incidence and estimated rates of residual risk for HIV, hepatitis C, hepatitis B and human T-cell lymphotropic viruses in blood donors in Canada, 1990-2000. CMAJ. 2003; 169:767-73.

13. Darbonne WC, Rice GC, Mohler MA, Apple T, Hebert CA, Valente AJ, et al. Red blood cells are a sink for interleukin 8 , a leukocyte chemotaxin. J Clin Invest. 1991;88:1362-9.

14. Banks WA, Farr SA, Morley JE. Entry of blood-borne cytokines into the central nervous system: effects on cognitive processes. Neuroimmunomodulation. 2002; 10:319-27.

15. Bux J, Sachs UJ. Pulmonary transfusion reactions. Transfus Med Hemother 2008;35:337-45

16. Sachs UJ, Wasel W, Bayat B, Bohle RM, Hattar K, Berghofer H, et al. Mechanism of transfusion-related acute lung injury induced by HLA class II antibodies. Blood. 2011;117:669-77.

17. Szekely A, Cserep Z, Sapi E, Breuer T, Nagy CA, Vargha P, et al. Risks and predictors of blood transfusion in pediatric patients undergoing open heart operations. Ann Thorac Surg. 2009;87:187-97.

18. Ootaki Y, Yamaguchi M, Yoshimura N, Oka S, Yoshida M, Hasegawa T. Efficacy of a criterion-driven transfusion protocol in patients having pediatric cardiac surgery. J Thorac Cardiovasc Surg. 2004;127:953-8.

19. Ando M, Takahashi Y, Suzuki N. Open heart surgery for small children without homologous blood transfusion by using remote pump head system. Ann Thorac Surg. 2004;78:1717-22.

20. Kotani Y, Honjo O, Nakakura M, Fujii Y, Ugaki S, Oshima Y, et al. Single center experience with a low volume priming cardiopulmonary bypass circuit for preventing blood transfusion in infants and small children. ASAIO J. 2009;55:296-9.

21. Miyaji K, Kohira S, Miyamoto T, Nakashima K, Sato H, Ohara K, et al. Pediatric cardiac surgery without homologous blood transfusion, using a miniaturized bypass system in infants with lower body weight. J Thorac Cardiovasc Surg. 2007; 134:284-9.

22. DeCampli WM. Invited commentary. Ann Thorac Surg. 2011;91:210-1.

23. Jonas RA, Wypij D, Roth SJ, Bellinger DC, Visconti KJ, du Plessis AJ, et al. The influence of hemodilution on outcome after hypothermic cardiopulmonary bypass: results of a randomized trial in infants. J Thorac Cardiovasc Surg. 2003; 126:1765-74.

24. Limperopoulos C, Majnemer A, Shevell MI, Rosenblatt B, Rohlicek C, Tchervenkov C. Neurologic status of newborns with congenital heart defects before open heart surgery. Pediatrics. 1999;103:402-8.

25. Limperopoulos C, Majnemer A, Shevell MI, Rosenblatt B, Rohlicek C, Tchervenkov C. Neurodevelopmental status of newborns and infants with congenital heart defects before and after open heart surgery. J Pediatr. 2000;137: 638-45.

26. Wypij D, Jonas RA, Bellinger DC, del Nido PJ, Mayer JE Jr, Bacha EA, et al. The effect of hematocrit during hypothermic cardiopulmonary bypass in infant heart surgery: results from the combined Boston hematocrit trials. J Thorac Cardiovasc Surg. 2008; 135:355-60.

27. Lacroix J, Hebert PC, Hutchison JS, Hume HA, Tucci M, Ducruet T, et al. Transfusion strategies for patients in pediatric intensive care units. NEngl J Med. 2007 356:1609-19.

28. Willems A, Harrington K, Lacroix J, Biarent D, Joffe AR, Wensley D, et al. Comparison of two red-cell transfusion strategies after pediatric cardiac surgery: a subgroup analysis. Crit Care Med. 2010;38:649-56. 